Chapter 4

\title{
Climate Change, Range Shifts and Multitrophic Interactions
}

\author{
Jeffrey A. Harvey and Miriama Malcicka \\ Additional information is available at the end of the chapter
}

http://dx.doi.org/10.5772/59269

\section{Introduction}

Climate change represents one of the most serious threats to biodiversity and ecosystem functioning. The current rate of temperature change, driven primarily by the human combustion of fossil fuels, far exceeds rates that have occurred in at least 10,000 years (lower Pleistocene) and perhaps much longer (IPCC, 2014). That last major climate change event precipitated a mass extinction that led to the sudden demise of many large quadrupeds, including such characteristic species as the woolly mammoth, woolly rhinoceros, mastodon, giant elk, sabertoothed tiger and dire wolf [1]. One of the major differences between landscapes at the time of previous climate change events and the current one is that the biosphere is now dominated by a single species, Homo sapiens sapiens, which has profoundly altered and simplified many terrestrial and aquatic ecosystems. Thus, in addition to climate change, natural ecosystems have been altered by other human-induced changes including deforestation, eutrophication, over-harvesting, the introduction of non-native species and various types of pollution. Consequently, species and populations are being challenged by multiple stressors, making it more difficult for them to adapt to rapid shifts in climate regimes. One can strongly argue that we no longer live in the Holocene but in the Anthropocene [2,3].

In a warming world, many species and populations are responding by changing various aspects of their life cycles, such as seasonal growth and phenology patterns, as well as by shifting their ranges pole-wards and/or to higher elevations $[4,5,6,7]$. The ability of species to shift their distributions is often limited by various eco-physiological constraints. These include the loss of habitat corridors through urban and agricultural expansion, which enable species to disperse over landscapes to other suitable habitat patches. Furthermore, some species lack traits, such as wings, which enable them to easily track changes in biotic conditions. As a result of these factors, we can expect ecological communities to change over time and for this to lead 
to unpredictable new assemblages which may or may not stabilize as temperatures continue to rise [8].

\section{Climate change and multitrophic interactions}

It has long been known that species do not exist in isolation in nature. Instead, the survival and persistence of species in food webs and communities is dependent upon an array of interactions with other organisms occurring over highly variable spatial and temporal scales. Indeed, ecologist Daniel Janzen [8] once remarked that 'the ultimate extinction is the extinction of ecological interactions'. More recently, Pimm and Raven [9] argued that for every species of plant that becomes extinct in the tropics, many tens of species dependent on that plant for food or shelter also disappear. Given that different species in food webs may respond differently to climate change, warming has the potential of unravelling and/or destabilizing plantinsect communities, and that these can trickle through to affect other trophic interactions, even involving vertebrates [10]. In this chapter we discuss the effects and potential consequences of warming on trophic interactions involving plants, insect herbivores and specialist natural enemies, focusing on parasitic wasps (or parasitoids). Parasitoids are insects that develop on or in the bodies of other insects, whereas the adults are free living [11]. Hosts attacked by parasitoids are often not much larger than the adult parasitoid, meaning they are under intense selection to allocate and utilize limited host resources for different and often competing fitness functions such as reproduction and survival [12]. It is well established that many parasitoids are often highly specialized in attacking only one or a few species of hosts in nature [11]. Warming-induced changes in the environment may therefore affect various aspects of the biology and ecology of food plants and insect herbivores dependent on them, and this may trickle up the food chain, in particular affecting natural enemies that are more specialized on certain host types. Parasitoids thus make model organisms for examining a range of biotic and abiotic constraints in the environment.

\subsection{Outline of the chapter}

The chapter will be broken down into separate sections examining the effects of warming on the biology and ecology of the three trophic levels separately, and then move on to integrate these interactions and to provide testable predictions for these processes. Given that insects are ecto-therms, it is by now well established that metabolic rate and the developmental program of insects is closely co-ordinated with changes in temperature. However, it is less well established how changes in temperature, as well as attendant changes in precipitation etc. will affect tightly linked two and three-trophic level interactions. On this basis, the chapter will be broken down thusly:

1. Range shifts in plants and effects to (i) primary [nutrients] (ii) secondary [defensive compounds] metabolites, as well as in plant volatiles under herbivore damage (HIPVs). How will changes in plant quality affect multitrophic interactions? 


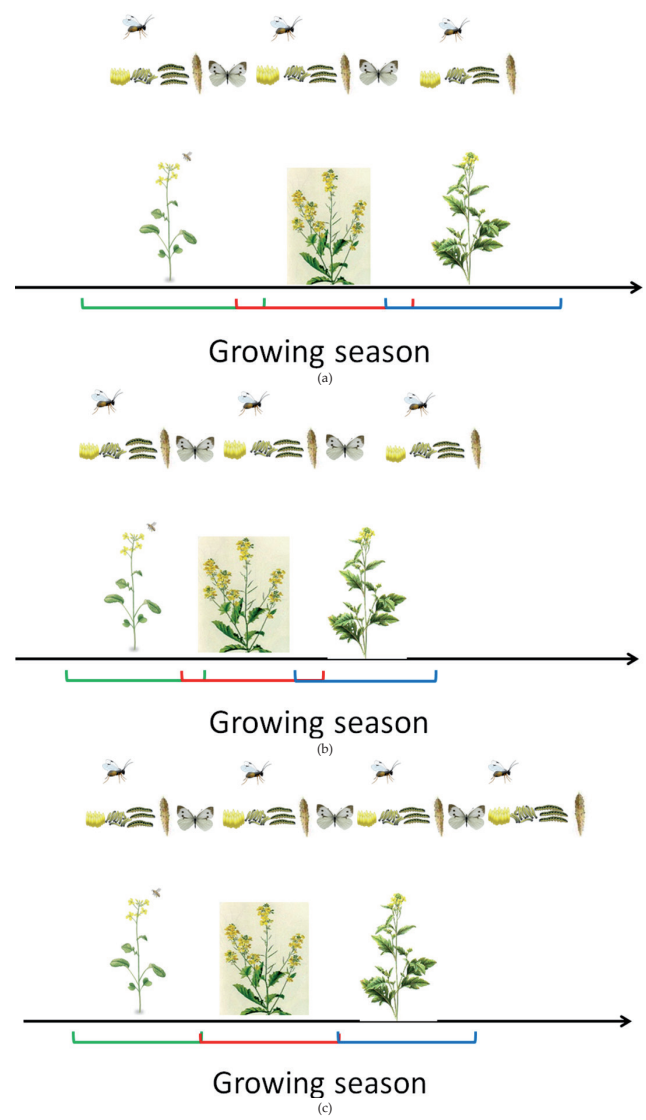

Figure 1. Phenological interactions involving three plant species, a specialist herbivore and its specialist endoparasitoid under normal conditions and under climate warming scenarios in Europe. In (A), Pieris brassicae (middle) the large cabbage white butterfly is trivoltine, and different generations lay their eggs on different species of large, short-lived annual brassicaceous (mustard) plants (bottom) that grow in aggregated populations. Different stages of the herbivore - eggs, young larvae, fully grown larvae, pupa and adult are shown. The mustards in turn grow only for 2-3 months during the year and at different times. Brassica rapa (wild turnip, left, green line) supports the first generation of $P$. brassicae, Sinapsis arvensis (charlock mustard, middle, red line) the second, and Brassica nigra (black mustard, right, blue line) the third. In turn, the gregarious endoparasitoid wasp, Cotesia glomerata (top) also has three generations where the adult wasps emerge in time to find and parasitize young caterpillars of $P$. brassicae, and emerge from fully grown caterpillars pupating on the food plant. In (B) and (C), warmer temperatures lead to dissociation of the multi-trophic interaction by differentially affecting the seasonal growth and activity patterns of the plants and insects. In (B), the plants are more strongly affected and their growing phenology is shifted to an earlier point in the season. However, the insects respond less to warming and their temporal life cycles become desynchronized with the growth cycles of their plants. There is also a period later in the season when few or no suitable plants are available. In (C), the plants only marginally shift their growing patterns to an earlier time point in the season, whereas the insects have an additional $\left(=4^{\text {th }}\right)$ generation later in the year. In both climate warming scenarios, there are gaps for the insects when food plants are scarce or absent. This could have profoundly negative consequences on the persistence of this trophic chain. 
2. Range shifts and outbreaks in herbivores in response to climate change and effects on plant responses and interactions with their natural enemies; range shifts in parasitoids: tracking their hosts or switching to novel native hosts? Examples of competitive interactions and potential displacement in interspecific competition will be explored.

3. The effects of temperature on insect growth, development and other traits. Given that insects are ectothermic, how will higher temperatures affect their development, and what will the consequences be for biotic interactions?

4. Changes in the seasonal phenology of multitrophic interactions; does warming differentially affect the growth/life cycles of plants, herbivores and their natural enemies, and what are the consequences for the persistence of these interactions?

5. How will warming potentially affect the dynamics of multi-trophic interactions, scaling up to food webs, communities and ecosystems, and will this in turn affect resilience and stability? What are the possible effects on top-down and bottom-up regulation?

An important theme of this chapter is to stress the importance of examining multi-species interactions under climate change scenarios. This entails a close examination of mechanisms as well as the consequences of warming in a community-related context. Thus far, both climate change and invasion ecology have been studied independently or have been largely restricted to the study of bi-trophic interactions (e.g. plant-herbivore) with very few studies going to three (or more) trophic interactions [13]. There are a number of excellent reviews which focus on each of these areas $[14,15,16,17]$ but only a few have begun to address community leveleffects, and again these generally do not integrate climate change with range shifts in plants and insects $[18,19,20]$. Fewer still have explored climate-change related range shifts on plantherbivore-parasitoid interactions at both reductionist and larger scale perspectives. The main aim of this chapter is therefore to explore and discuss how climate change and related abiotic changes (e.g. precipitation) will affect multi-trophic interactions from both the perspective of mechanisms and processes, scaling up from individuals to communities and ecosystems. We will discuss the potentially cascading effects of climate warming and other parameters related to climate change on ecosystems, suggesting that many will be simplified (Fig 1.), reducing their resilience against other natural and anthropogenic challenges in the environment.

\section{Range shifts in plants}

Two aspects of warming will affect the structure of plant communities. The first involves native plants which may be adapted to cooler conditions and thus become increasingly stressed as conditions warm. This is especially true for plant species growing at the southern edge of their ranges. The second involves plants which shift their ranges northwards in order to track warming and to exploit more optimal thermal conditions. These plants will increasingly expand into habitats occupied by native plants, leading to potential increases in competition and, at least to some extent, rearrangement in plant community structure. As the climate warms, we may expect physiological and metabolic responses in both native and range 
expanding plants that will in turn potentially affect the behaviour and performance of higher trophic level consumers associated with them. More specifically, the metabolic changes in plants may be borne out on traits such as primary and secondary metabolism which play a key role in insect nutrition and plant defence responses. Plant volatiles, which are often induced in response to herbivore damage and which potentially have many functions, might also be affected by warming or in response to new selection pressures in range expanding plants. At the same time, range expanding plants may, at least partially, escape from some of their co-evolved enemies, such as herbivores and pathogens, also affecting the costs and benefits of metabolic investment into plant defences. Below, we examine these areas in more detail.

\section{Primary and secondary metabolism}

Plant tissues contain various concentrations of nutrients, with carbon $(\mathrm{C})$, nitrogen $(\mathrm{N})$, and phosphorus $(\mathrm{P})$ being considered as the most important, as well as amino acids [21]. Although atmospheric $\mathrm{CO}_{2}$ concentrations are deterministic at various scales, and are rising slowly at about 2-3 ppm annually, temperatures are not. Thus one can question the efficacy of experiments that expose plants (and insects) to extremely high concentrations of $\mathrm{CO}_{2}$ (e.g. $450 \mathrm{ppm}$ and higher) when these levels are not expected to be reached for several decades. However, there is no way to successfully circumvent this obstacle, and many studies exposing plants to higher $\mathrm{CO}_{2}$ levels have been conducted. Many have shown that under increased $\mathrm{CO}_{2}$ regimes attendant with climate change that plants will possibly take up more $\mathrm{C}$ at the potential expense of foliar levels of $\mathrm{N}$ and $\mathrm{P}[22,23,24]$ and that changes in concentrations of other nutrients, such as amino acids, will also occur [25]. (However, these processes are indeed complex - for instance they vary in plants with different metabolic $C$ pathways as well as in different successional stages but a highly detailed discussion of this is not possible here). $\mathrm{N}$ is considered a limiting nutrient for insect development $[26,27,28,29]$ and it has been suggested that a reduction in foliar concentrations of $\mathrm{N}$ will lead to compensatory feeding in herbivores to ensure optimal levels of this nutrient are acquired [26,30,14,31]. For range expanding plants in a warming world, it is difficult to extrapolate cause-and-effect relationships related to temperature and precipitation, unless atmospheric changes in $\mathrm{CO}_{2}$ are also taken into account.

Most plants also produce secondary metabolites (or allelochemicals) whose primary function is considered to be defence against antagonists such as pathogens and herbivores [32,33,34,35]. There is a vast array of different types of allelochemicals produced by plants that are based on the phylogeny of a species group, often at the family level [36]. For instance, one can find glucosinolates, alkaloids, iridoid glycosides, furanocoumarins and many other allelochemicals produced by plants in different families. These toxins are often inducible, meaning that they are found in basal levels in intact plant tissues but markedly increase after tissue damage [37, 35]. These compounds have long been known to affect the behaviour and performance of insects that are intimately associated with the plants that produce them. High levels of phytotoxins in plant tissues can impair the development and hence fitness of herbivores, through increased rates of mortality, extended development time and reduced adult size [38, 
39,40,41,42,43,44]. These effects often differ between specialist and generalist herbivores. Generalists usually do not possess highly refined mechanisms of dealing with specific secondary plant compounds, but instead rely on general responses, (e.g. P-450 mono-oxygernases) that are effective against a range of different metabolites [45]. However, they are very often less effective than the mechanisms employed by specialists which have strongly coevolved histories with certain types of plant phytotoxins. For this reason, specialists are frequently assumed to be in a co-evolutionary 'arms race' with plant defences [46] in which increased herbivory leads to increased plant defences which in turn leads to adaptations on the part of the herbivore and so on in a 'Red Queen' type stalemate scenario. In fact, elevated levels of toxins actually stimulate feeding and oviposition behaviour in the many specialist herbivores [35]. Despite this, very well defended plants are often problematical even for specialists [47].

The development of natural enemies such as parasitoid wasps is also known to be affected by host attributes as mediated through the quality of the host diet [41,42]. High levels of plant toxins ingested by the host can also detrimentally affect the growth and survival of immature parasitoids and even hyperparasitoids one trophic level higher [48,49]. One major phylogenetic constraint on parasitoid larvae is that the alimentary tract is not externally connected until they terminate the relationship with the host [50]. Therefore, all host tissues ingested during development are stored in the body pending the voiding of the meconium (or even later as an adult). This includes deleterious materials such as plant toxins that were stored in the body of the herbivore host. If concentrations of these toxins become too high, then it is possible that the developing parasitoid larvae cannot safely store them and will die precociously as a result. It is interesting that the diversity of many parasitoid taxa is higher in temperate than in tropical biomes, a trend that contradicts that shown in most other groups of insects. Bolton [51] hypothesized that tropical vegetation is generally much more toxic than vegetation in the temperate zone, and that parasitoids have not been able to adapt to hosts that ingest and store these toxins in their body tissues (the 'nasty-host-hypothesis').

Several climate-change related effects on plant allelochemistry are possible, and these may trickle their way through trophic webs. Elevated $\mathrm{CO}_{2}$ regimes will also affect plant allelochemistry in potentially different directions depending upon whether a plant's defence chemistry is C-or N-based. Plants with C-based allelochemistry may become more toxic (e.g. better defended) whereas the opposite may occur with plants with N-based allelochemistry $[52,53,54,55,56,57]$. A second affect will be that warming, along with changes in precipitation, as well as reduced or extended drought periods attendant with climate change will affect metabolic allocation by plants to secondary defense metabolites. Higher temperatures can sometimes lead to a reduction in plant allocation to direct defence [58]. Veteli [59] found that elevated $\mathrm{CO}_{2}$ and temperature increased plant growth but had opposite effects on the growth rate of an insect herbivore. A third effect will be that range shifting plants will escape from some of their co-evolved herbivore enemies, leading to changes in metabolic allocation towards plant defence [60]. If native specialist and generalist herbivores select for high chemical defences in native plants, then range-expanding plants may invest less in these defences if they are attacked by fewer herbivores (and thus suffer less herbivore damage) in 
their new range [the 'enemy-release hypothesis' [ERH],[61,62,63] and more towards other functions, such as growth that enable plants to outcompete natives (the 'evolution of increased competitive ability hypothesis' [EICA], [62,64]. A third hypothesis, the 'shifting defence hypothesis' [SDH], posits that co-evolved specialists are adapted to high concentrations of plant allelochemicals, driving selection for a reduction in them to make them less attractive as oviposition sites [65]. In new habitats, these plants escape their specialists but attract more generalists, selecting for an increase in chemical defences. Lastly, many invasive plants bring with them novel secondary metabolites to which the native herbivore fauna is not adapted and which therefore allows the plant to invest metabolic energy to other vital functions (the 'novel weapons hypothesis' [NWH], [66,67]. Thus only a single study has considered climate change-mediated changes in plant communities on natural enemies of the herbivores on native and invasive plants [68]. This revealed that there may be shifts in the intensity of natural enemy-mediated top down trophic cascades versus bottom-up plant-mediated effects on herbivores on natives and invasives. However, it is far too early to draw conclusions as many more studies are needed to tease out potential patterns in communities where shifts in plant composition are occurring as a result of warming.

There is ample evidence in support of these different hypotheses for inter-continental invasions $[63,69]$. However, intra-continental invasions based on climate-change related range shifts $[70,71]$ are likely to have more subtle effects on plant-consumer interactions because many insects can track their food plants as they move pole-wards [72]. As a result, consistent patterns remain elusive. Engelkes [68] found that range expanding plants in the Netherlands were more toxic to naïve herbivores than related natives, and that the range-expanders also produced higher levels of general defence compounds (phenolics). Fortuna [73] compared allelochemistry and herbivore performance in native and range-expanding populations of warty cabbage (Bunias orientalis) and reported that the insects were larger and survived better on the range-expanding than on the native populations. Moreover, the authors found both quantitative and qualitative differences in plant allelochemistry between the native and range expanding plants. It appears that $B$. orientalis is comparatively rare and local in its native range, which is perhaps evidence of biotic resistance amongst coevolved members of the native plant community as well as more top-down control exerted by native co-evolved herbivores and/or pathogens $[61,64]$. Other studies have found little or no differences in insect performance on native and range-expanding populations in plants [74].

Plants also release chemically-based odours via the production of volatiles that are often induced by stresses such as herbivory $[75,76,77]$. The precise function of these volatiles is unclear and remains the subject of considerable debate $[78,79,80,81]$. It is known that these volatiles are used by insects to locate plants on which to oviposit $[75,82]$ or on which natural enemies find their prey or hosts $[83,84,85,86]$. If insects can drive selection for types and concentrations of volatiles, then changes in top-down pressures as plants are released from their enemies (e.g. herbivores) or potential allies (e.g. parasitoids) may also alter volatile profiles over time. However, thus far the effect of plant volatiles in range expanding plants on native natural enemies has received virtually no attention. Fortuna [87] found that adult females of the large cabbage white butterfly, Pieris brassicae, preferred to oviposit on shoots of 
a native brassicaceous plant, Sinapis arvensis, over those of a range expander, Bunias orientalis. Herbivore performance was higher on the native plant. However, its major natural enemy, the parasitoid Cotesia glomerata, did not distinguish between volatiles of the two plants. This suggests that herbivores and parasitoids may respond to different kinds of volatiles - herbivores clearly on those released by the plant alone and specialist natural enemies to a combination of plant and host-or prey-related odours.

A recent study by Yuan [88] laid out a possible framework for the effects of climate change on plant volatiles, and projected this to the community level. They argued that patterns are likely to be variable and association-specific, because of the immense complexity in the blends that make up a plant's volatile profile. Moreover, other anthropogenic stresses must be factored in, leading to highly unpredictable scenarios across different scales of space and time. They urged that more studies with different systems are necessary to tease out mechanisms that may cascade up to affect higher trophic level consumers.

\section{Effects of climate change on insect growth and development}

Insects, like all invertebrates, are ectotherms and thus they are highly susceptible to changes in temperature as well as other abiotic processes linked with climate change [14,15]. Many studies have examined how insects across different trophic levels respond to variations in temperature [14]. Rarely have these responses, however, been placed within the context of climate change, perhaps because warming has only been broadly acknowledged in the past 20 years or so by the scientific community. As with plants, insects can respond in two ways to local warming regimes. First, they must adapt behaviourally, morphologically and physiologically to such processes as an increased incidence of heat waves and other attendant stresses such as droughts or higher precipitation regimes or an increase in frost-free periods [15]. Second they can shift their ranges and move pole-wards or to higher elevations (below).

Many studies have reported that the survival, development rate and adult body mass of insect herbivores and their natural enemies are affected by rearing temperatures [89]. Much less attention has been paid to transient periods of high or low temperatures (e.g. combining them under the umbrella of a single experiment, thus creating a more realistic picture of events transpiring in nature) or rainfall. It is by now known that climate warming is likely to generate more extreme weather events at local scales, rather than simply resulting in gradual changes that are measured at large spatial scales across the biosphere. When confronted with these conditions, insects have to adapt or to move to new habitats where conditions are more suitable. In time, the latter will result in range shifts, a phenomenon by now well described in many studies (see next section, below). Those insects that 'remain behind'will exhibit physiological responses to warming and phenomena associated with its such as an increase in heat waves and changes in precipitation. 


\section{Range shifts in herbivores and their natural enemies}

As with other organisms, various insect taxa are adapted to climate windows and have welldefined ranges which coincide with both biotic and abiotic conditions [90]. Climate warming is already known to be driving demographic and geographic responses in insects $[6,8,14,91,92]$. Range shifts in herbivores and their natural enemies depend on a number of ecological factors that go beyond warming and which are often complex. For specialist herbivores that feed on only one or a few related plant species, a major impediment to movement is the availability of nutritionally suitable plants in their new habitats [6]. Generalist herbivores, on the other hand, may benefit if they are able to feed on a range of unrelated plants in both their native and invasive ranges. For many herbivores this is not a problem if their food plants also track the warming climate or if related plants with similar allelochemistries are also found in the new ranges of the insects. The oak processionary caterpillar (Thaumetopoea processionea) has expanded its range dramatically to the north within Europe over the past 30 years, coinciding with the recent warming episode [93]. Suitable oak trees on which the larvae can feed and develop, are found over much of Europe, helping to facilitate its spread. Its close relative, the pine processionary caterpillar (Thaumetopoea pityocampa), has also spread northwards as a result of recent warming and is projected to arrive in the Benelux region in the near future [94, 95]. Both species are considered as major health hazards owing to the production of numerous urticating hairs in mid-and late larval instars that contain soluble proteins and which are highly irritating to the skin and mucous membranes of humans [96]. The oak processionary caterpillar is actually more abundant now in many parts of its invasive than in its native range, perhaps because its specialist natural enemies have not effectively tracked its northwards expansion [93]. This is a worrying pattern that, if repeated in many trophic interactions, could facilitate pest outbreaks with large attendant economic costs.

Many other insects are known to be expanding into new habitats as a result of climate warming $[7,97,98]$. As they do so, they interact with native plants and their associated arthropod communities. The broader ecological outcome of these interactions is open to considerable debate. There is the possibility of community reorganization or reassembly as some species compete with and potentially displace others (see more detailed discussion of this below). Studies examining a suite of ecophysiological processes that underpin the ways in which these interactions work are urgently required. For instance, different species within food webs may each respond differently to changes in abiotic conditions such as temperature and moisture. The diamondback moth (Plutella xylostella) is native to Africa and the Mediterranean region, but has been introduced over many parts of the world where it is a serious pest of cabbages and related crops [99]. The moth only began to successfully overwinter in central Europe in the past 20 years, allowing to have two generations per year and to build up numerically faster by mid-summer [99]. It is attacked by several larval endoparasitoids, each of which exhibits differential responses to temperature. Recent warming in central Europe appears to favor thermophilic parasitoids like Costesia vestalis and Dolichogenidea sicaria over cool-favoring species like Diadegma semiclausum [99, J. Harvey, personal observations]. In addition to range expansions, many native insects will benefit from warming as a result of longer growing seasons and more favorable conditions for 
populations to grow. There is already evidence that some species are experiencing outbreaks as a result of warming as well as range expansions [100].

\section{Effects of warming on the seasonal phenology of multitrophic interactions}

Jeffs and Lewis [17] examined the potential effects of climate warming on host-parasitoid interactions and developed three primary ways in which parasitoids might respond to warming: (1) by shifting distributions polewards or to higher elevations; (2) altering their phenology; (3) adjusting to persist in their current ranges through phenotypic plasticity or evolutionary adaptations. However, this ignores the potentially negative effects of a failure to respond to warming, or else the consequences of local changes on the survival and persistence of parasitoids. For example, warming is occurring so rapidly in many places that many species or populations may not be able to adapt in sufficient time. The authors fail to discuss the physiological costs of warming and how this might affect the acquisition and metabolic allocation of resources by the larvae (from the host) and the adult (from both host and/or nonhost sources). If development of immature stages is negatively affected, this might have profound effects on adult fitness and thus lead to declines and possible extinction. Furthermore, phonological shifts depend on the ability of the parasitoid not only to track the host but the host's foodplant(s). Changes in important abiotic parameters may unravel trophic interactions if the species in these links respond differently to warming in terms of their life cycles. This has already been demonstrated in oak-winter moth interactions and the effects of this are negatively affecting the reproductive success of both migratory and resident insectivorous birds. There is a possibility that parasitoids of winter moths are also being negatively affected by warming. Some plants that are vital for the development and survival of specialist herbivores may also shift their seasonal growth patterns. For instance, interactions involving the large cabbage white butterfly, Pieris brassicae, its natural food plants and a specialist gregarious endoparasitoid, Cotesia glomerata, are complex in the context of life-history interactions involving the various parties. The herbivore and parasitoid each have 2-3 generations per year, each of which must seek out new food plant species in which to exploit. This is because most of its suitable food plants - brassicaceous species - are short-lived annuals or biennials, whereby different species grow at different times of the growing season [101]. Some species, such as Brassica nigra, grow early in the spring, whereas others, including Sinapis arvensis and $B$. nigra grow in late spring and summer respectively. The consequences of warming on the phenology of this trophic interaction may critically hinge on how the plants and insects each respond to increasing temperatures, and how this in turn affects the availability and suitability of the resources which they exploit as food. For the herbivore, of course, this means the availability of nutritious shoots on which the caterpillars feed, and for the parasitoid young caterpillars in which the female wasps oviposit clutches of up to 50 eggs. Warming will certainly increase the number of generations the insects have, and there already indications, based on populations in the Mediterranean region that up to 4 generations are indeed possible in more central and northern parts of Europe. However, if plant growth is temporally advanced 
(something that occurred in 2014) then later generations of the insects may emerge into habitats with little plant food available. There are, however, many possible scenarios, whereby the insects may experience neutral or negative effects of warming on their survival and fitness. Furthermore, this example is hardly likely to be an isolated one; indeed, many trophic interactions involving specialized consumers are under the same constraints.

\section{Climate warming in the context of larger ecological scales}

Thus far, the relationship between temperature and insect behavior and development have been largely confined to pairwise interactions involving a plant and a herbivorous insect, or even the insect alone when reared on an artificial medium. Slightly more complexity has been achieved by incorporating a predator or a parasitoid into these studies, but the vast majority of them have been focused on optimal rearing conditions for biological control rather than on anthropogenic stresses such as climate change in natural and managed ecosystems. Indeed, in other fields where anthropogenic stresses are involved, such as invasive species or habitats loss, little attention has often been paid to insects in a multitrophic framework $[10,13,102]$. Climate change certainly represents a serious challenge to insects across vastly different scales of space and time because it will have cascading effects on a wide range of ecological characteristics and processes in habitats. An important challenge is to scale up the results of smallscale studies to see how these play out in communities, ecosystems and biomes. In this context we need to understand how biodiversity over large scales regulates ecosystem-level processes and how warming, by weakening processes and interactions at smaller scales, will affect this regulation.

The traditional approach in examining the relationship between biodiversity plays in ecosystem functioning has been based species interactions and the consequences of such interactions for community structure and function. These interactions can be classified as direct, involving pairwise interactions between species (e.g. predation/parasitism) or indirect, involving mediation by a third party [103]. Therefore, studying how biodiversity influences ecosystem functioning in multitrophic systems (involving mediation by a third party) is important for several reasons: (1) multiple trophic levels represent the core of ecosystems [104]; (2) as multitrophic diversity increases, average ecosystem properties could increase, decrease, stay the same or follow more complex non-linear patterns [105]. Consequently, as the number of species change within a community, the occurrence and significance of (in)direct interactions will also change. These, in turn, may be modified by abiotic factors, which may generate cascading reactions that generate large ecological changes with important ecological consequences $[103,106]$.

Three of the well-documented global changes mediated by human activities are: increasing concentrations of carbon dioxide in the atmosphere; alterations in the biogeochemistry of the global nitrogen cycle; and ongoing land use/land cover change [106]. Human activity is now considered as the prime driver of global environmental change [106,107,108,109]. However, our ability to generate linkages at spatial (landscape) scales relevant to the human enterprise 
is limited at present [110]. Most importantly, the consequences of biodiversity loss on ecosystem services (e.g. primary and secondary production, nutrient cycling, pest control, pollination, etc.) is poorly understood, as is our knowledge of the effects of warming on ecosystem processes [105]. Therefore, understanding an array of mechanisms that drive the biodiversityecosystem functioning relationship is thus difficult to evaluate in multitrophic systems [105], because of the unexpected consequences of warming on species interactions and demographics e.g. when the biology of one species is influenced by the biology of another species [111]; under simultaneously changing landscape characteristics such as habitat availability and landscape structure that affect biodiversity [112,113]; through the loss and/or fragmentation of habitats that drive changes in species abundance with both winners and losers [114].

Multitrophic interactions involve microbes, pathogens, plants, animals and other functional groups that are found in different positions of the food chain and provide vital functions to communities and ecosystems [115]. Here, we focus on organisms inextricably linked to plantinsect interactions. Microorganisms from diverse environments have played an important role in ecosystem sustainability. Since the spatial and temporal stresses of the microbial system may be quite different from those of plants and animals [116], many studies of the ecological responses to global changes have suggested that belowground processes, often mediated by soil microorganisms, are central to the response of ecological systems to global change [117]. Below-ground microbial mediated processes can both immobilize and release nutrients that limit primary production and can influence the long-term response of ecosystems to global change [118]. Investigations into microbial parameters involved in soil quality are increasing $[118,119,120]$ and it has been shown that human activity can directly or indirectly affect the functioning and diversity of the soil community [116,121] and these effects are transferred aboveground where they effect the structure and function of plant-insect communities $[19,122,123]$. Bardgett [124] described some potential outcomes for soil microbes and carbon exchange that include: (i) increases in soil carbon loss by respiration and in drainage waters as dissolved organic carbon due to stimulation of microbial abundance and activity, and enhanced mineralization of recent and old soil organic carbon [125,126]; (ii) stimulation of microbial biomass and immobilization of soil $\mathrm{N}$, thereby limiting $\mathrm{N}$ availability to plants, creating a negative feedback that constrains future increases in plant growth and carbon transfer to soil [127]; (iii) increased plant-microbial competition for $\mathrm{N}$, leading to reduced soil $\mathrm{N}$ availability and microbial activity and suppression of microbial decomposition and ultimately increased ecosystem carbon accumulation [117]; (iv) increased growth of mycorrhizal fungi $[128,129]$, which receives carbon in the form of photosynthate directly from the host plant and retains this carbon, controlling its release to the soil microbial community [130]; and changes in root exudation that are known to play a potentially important role through the promotion of methanogenesis and hence carbon loss from soil as methane [131], although the mechanisms involved in this process are poorly understood.

The response of the soil free-living bacterial group ( $\beta$ subclass of the Proteobacteria) on simulated multifactorial global change was investigated in grassland vegetation dominated by annual grasses and forbs growing in sandstone-derived soil [118]. The results demonstrate that shifts in community composition were associated with increases in nitrification, but 
changes in abundance were not, confirming that microbial communities can be consistently altered by global changes and that these changes can have implications for communities and ecosystems.

Alternatively, atmospheric $\mathrm{CO}_{2}$ on microbial decomposition in peat was found to be greater than when these factors operated alone, creating a stronger positive feedback on carbon loss from soil as DOC (dissolved organic carbon) and respiration [126].

Soil microbes and their activities are inexorably linked to above and below ground communities and therefore it is necessary to understand the effects of climate change on carbon budgets [124]. However, it is important to be aware also of adverse effect of soil microbes on multitrophic interactions, mostly in the case of pathogens. Soil borne pathogens can significantly alter the spatial distribution and reduce the yield and quality of plants [132,133]. Climate change generally has a beneficial effect on pathogen suppression and stress tolerance [115]. Bacteria, fungi and nematodes perform specific functions that help suppress the infection and colonization of plant roots by pathogens in the rhizospehere [115].

Plants play a major role in controlling and mediating directly or indirectly all soil multitrophic interactions [115] and contribute to ecosystems on by providing food, shelter or "ecological islands" for microbes, fungi, insects, and other organisms. However, dead plants also continue to supply the environment with nutrients. Thus, qualitative and quantitative changes in plant physiology, chemistry, tissue composition and signaling pathways under rising $\mathrm{CO}_{2}$ and temperature regimes may influence the entire cascade of above and below-ground multitrophic interactions $[134,135,136,137]$. Moreover, the geographical distribution of plants is also affected by changing temperature and precipitation that alter the structure of plant communities at larger scales and which in turn generate new (positive or negative) trophic interactions [138]. The principle effect of changes in the spatial distribution of plants is also influenced by the presence or absence of mutualists (pollinator) and antagonist (pathogen and herbivore) in a changing environment [139] as well as intra-interspecific competitors (taller plants replace lower congeneric species) [140]. On the other hand, plant phenology is temperature-sensitive with strong connections with photoperiod [141]. Accordingly, there is critical springtime photoperiod, which is an important pre-requisite before floral development can begin $[141,142]$. Net photosynthesis (primary production) typically peaks within the range of normal temperatures [143,144], however increasing temperatures can shift this peak and extending the growing season and consequently accelerate plant growth [145]. This situation can lead to key differences with respect to interactions with insect mutualists or antagonists [16] and subsequently changes in the population dynamics can alter evolutionary trajectories [146], creating "evolutionary noise" with unpredictable consequences for the strength and persistence of trophic interactions. While evidence of adaptive responses via variation among genotypes in response to increasing temperature has been described in a marine parasite Maritrema novaezealandensis [147], the extinction of local populations of the angiosperm Fagus sylvatica still occurred at the southern range margin despite strong signals of genetic adaptation in this species to climate warming $[148,149]$. This variation in responses at the species level makes it virtually impossible to predict the effects of climate change on trophic interactions, although available evidence suggests that there will be many more losers than winners [6] and 
as a result we can expect multitrophic (ecosystem) interactions to be simplified (Fig. 2) and ecosystems therefore to become less stable and resilient [150].
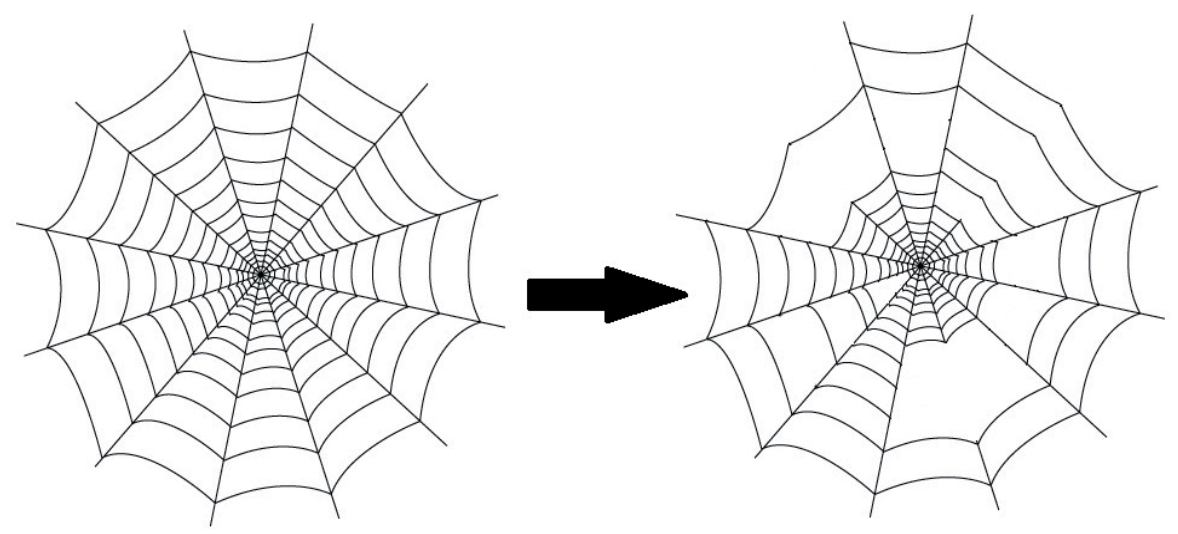

Figure 2. Variation in responses at the species level makes it virtually impossible to predict the effects of climate change on trophic interactions, although available evidence suggests that there will be many more losers than winners and as a result we can expect ecosystem interactions to be simplified and ecosystems therefore to become less stable and resilient.

\section{Summary and future directions}

Climate change clearly represents a major challenge to biodiversity at all levels of organization. This includes physiological and behaviorial responses of individual species through trophic interactions and beyond to the scale of communities and ecosystems. Given that they are ectotherms, insects will respond to warming in a number of ways. First, they may seek out micro-climates with more optimal temperatures for biological activity; second, they may shift their diel patterns of activity to coincide with more optimal temperature regimes; third they will adjust their broader distributions either moving to higher elevations or polewards. However, these responses also critically depend upon interactions with other species, including both resources (e.g, plant for herbivores and herbivores for predators) as well as indirect interactions with species two levels or more apart on the food chain.

Thus far, few studies have explored climate change on trophic interactions integrating three or more levels of a food chain. Instead, the main focus thus far has been on descriptive studies or else on two-trophic level interactions, with little attention paid to members higher up the food chain (e.g. parasitoids and hyperparasitoids), especially in a multitrophic framework. Given the paucity of studies in this area, it is virtually impossible to predict larger scale consequences of warming for communities and ecosystems and the services that emerge from them. It is therefore important to scale up the biological effects of warming on individual 
species of producers (plants) and consumers (herbivores and natural enemies) to trophic chains and from there to communities, in order to better understand the potential consequences on the stability and resilience of ecosystems and the biomes in which they are embedded. This is a daunting challenge, but one that must be tackled if we are to develop predictive power of climate change effects on natural and managed ecosystems. Another important area is to combine warming in an above-and below ground approach integrating trophic interactions occurring amongst insects and other invertebrates in both compartments, an area that is now being increasingly considered in community-based research [151].

\section{Author details}

Jeffrey A. Harvey ${ }^{1,2^{*}}$ and Miriama Malcicka ${ }^{2}$

*Address all correspondence to: j.harvey@nioo.knaw.nl

1 Netherlands Institute of Ecology, Department of Terrestrial Ecology, Wageningen, The Netherlands

2 VU University Amsterdam, Department of Ecological Sciences, Animal Ecology, Amsterdam, The Netherlands

\section{References}

[1] Graham RW, Lundelius EL Jr. Coevolutionary disequilibrium and Pleistocene extinctions. 1984.

[2] Zalasiewicz J, Williams M, Haywood A, Ellis M. The Anthropocene a new epoch of geological time?. Philosophical Transactions of the Royal Society A Mathematical, Physical and Engineering Sciences 2011; 369(1938) 835-841.

[3] Steffen W, Persson Å, Deutsch L, Zalasiewicz J, Williams M, Richardson K, Crumley C. et al. The Anthropocene From global change to planetary stewardship. Ambio 2011; 40(7) 739-761.

[4] Hughes L. Biological consequences of global warming is the signal already apparent? Trends in Ecology \& Evolution 2000; 15(2) 56-61.

[5] Post E, Forchhammer MC. Synchronization of animal population dynamics by largescale climate. Nature 2002; 420(6912) 168-171.

[6] Thomas CD, Cameron A, Green RE, Bakkenes M, Beaumont LJ, Collingham YC, Barend FN Erasmus et al. Extinction risk from climate change. Nature 2004; 427(6970) 145-148. 
[7] Parmesan C. Influences of species, latitudes and methodologies on estimates of phenological response to global warming. Global Change Biology 2007; 13(9) 1860-1872.

[8] Janzen DH. Tropical dry forests. The Most Endangered Major Tropical Ecosystem, Pp en EO Wilson, Biodiversity; 1988.

[9] Pimm SL, Raven P. Biodiversity extinction by numbers. Nature 2000; 403(6772) 843-845.

[10] Cronin JT, Haynes KJ. An invasive plant promotes unstable host-parasitoid patch dynamics. Ecology 2004; 85(10) 2772-2782.

[11] Godfray HCJ. Parasitoids, behavioral and evolutionary ecology. Princeton University Press; 1994.

[12] Jervis MA, Ellers J, Harvey JA. Resource acquisition, allocation, and utilization in parasitoid reproductive strategies. Annual Review of Entomology 2008; 53 361-385.

[13] Harvey JA, Bukovinszky T, van der Putten WH. Interactions between invasive plants and insect herbivores a plea for a multitrophic perspective. Biological Conservation 2010; 143(10) 2251-2259.

[14] Bale JS, Masters G, Hodkinson I, Awmack C, Bezemer TM, Brown V, Butterfield J, Buse A, Coulson J, Farrar J. Herbivory in global climate change research direct effects of rising temperature on insect herbivores. Global Change Biology 2002; 8(16) 1-16.

[15] Hance T, Van Baaren J, Vernon P, Boivin G. Impact of extreme temperatures on parasitoids in a climate change perspective. Annual Review of Entomology 2006; 52(1) 107.

[16] Jamieson MA, Trowbridge AM, Raffa FK, Lindroth RL. Consequences of climate warming and altered precipitation patterns for plant-insect and multitrophic interactions. Plant Physiology 2012; 160 (4) 1719-1727.

[17] Jeffs CT, Lewis OT. Effects of climate warming on host-parasitoid interactions. Ecological Entomology 2013; 38(3) 209-218.

[18] Tylianakis JM, Didham RK, Bascompte J, Wardle DA. Global change and species interactions in terrestrial ecosystems. Ecology Letters 2008; 11(12) 1351-1363.

[19] Van der Putten WH, de Ruiter PC, Bezemer TM, Harvey JA, Wassen M, Wolters V. Trophic interactions in a changing world. Basic and Applied Ecology 2004; 5(6) 487-494.

[20] Van der Putten WH, Macel M, Visser ME. Predicting species distribution and abundance responses to climate change why it is essential to include biotic interactions across trophic levels. Philosophical Transactions of the Royal Society B Biological Sciences 2010; 365(1549) 2025-2034.

[21] Epstein E. Mineral nutrition of plants principles and perspectives. 1972. 
[22] Ryan MG. Effects of climate change on plant respiration. Ecological Applications 1991; 1(2) 157-167.

[23] Melillo JM, McGuire AD, Kicklighter DW, Moore B, Vorosmarty CJ, Schloss AL. Global climate change and terrestrial net primary production. Nature 1993; 363(6426) 234-240.

[24] Cramer W, Bondeau A, Woodward FI, Prentice IC, Betts RA, Brovkin V, Cox PM et al. Global response of terrestrial ecosystem structure and function to $\mathrm{CO} 2$ and climate change results from six dynamic global vegetation models. Global Change Biology 2001; 7(4) 357-373.

[25] Bezemer TM, Jones TH. Plant-insect herbivore interactions in elevated atmospheric $\mathrm{CO}_{2}$ quantitative analyses and guild effects. Oikos 1998; 212-222.

[26] Mattson Jr, William J. Herbivory in relation to plant nitrogen content. Annual Review of Ecology and Systematics 1980; 119-161.

[27] Chapin III FS, Vitousek PM, Van Cleve K. The nature of nutrient limitation in plant communities. American Naturalist 1986; 48-58.

[28] Lambers $\mathrm{H}$. Rising $\mathrm{CO}_{2}$, secondary plant metabolism, plant-herbivore interactions and litter decomposition. Vegetatio 1993; 104(1) 263-271.

[29] Elser JJ, Hayakawa K, Urabe J. Nutrient limitation reduces food quality for zooplankton Daphnia response to seston phosphorus enrichment. Ecology 200; 82(3) 898-903.

[30] Lincoln DE. The influence of plant carbon dioxide and nutrient supply on susceptibility to insect herbivores. Vegetatio 1993; 104(1) 273-280.

[31] Berner D, Blanckenhorn WU, Körner C. Grasshoppers cope with low host plant quality by compensatory feeding and food selection N limitation challenged. Oikos 2005; 111(3) 525-533.

[32] Rosenthal GA, Berenbaum MR. Herbivores Their interactions with secondary plant metabolites Ecological and Evolutionary Processes. Vol. 2. Academic Press; 1992.

[33] Bennett RN, Wallsgrove RM. Secondary metabolites in plant defence mechanisms. New Phytologist 1994; 127(4) 617-633.

[34] Karban R, Baldwin IT. Induced responses to herbivory. Chicago University of Chicago Press; 1997.

[35] Schoonhoven LM, van Loon JJA, Dicke M. Insect-Plant Biology, Ed 2. Oxford University Press, Oxford; 2005.

[36] Wink M. Evolution of secondary metabolites from an ecological and molecular phylogenetic perspective. Phytochemistry 2003; 63(1) 3-19.

[37] Bourgaud F, Gravot A, Milesi S, Gontier E. Production of plant secondary metabolites a historical perspective. Plant Science 2001; 161(5) 839-851. 
[38] Barbosa P, Krischik VA, Jones CG. Microbial mediation of plant-herbivore interactions. John Wiley \& Sons; 1991.

[39] Hunter MD, Linnen CR, Reynolds BC. Effects of endemic densities of canopy herbivores on nutrient dynamics along a gradient in elevation in the southern Appalachians. Pedobiologia 2003; 47(3) 231-244.

[40] Harvey JA, Van Nouhuys S, Biere A. Effects of quantitative variation in allelochemicals in Plantago lanceolata on development of a generalist and a specialist herbivore and their endoparasitoids. Journal of Chemical Ecology 2005; 31(2) 287-302.

[41] Harvey JA. Factors affecting the evolution of development strategies in parasitoid wasps the importance of functional constraints and incorporating complexity. Entomologia Experimentalis et Applicata 2005; 117(1) 1-13.

[42] Ode PJ, Plant chemistry and natural enemy fitness effects on herbivore and natural enemy interactions. Annual Review of Entomology 2006; 51 163-185.

[43] Gols R, Wagenaar R, Bukovinszky T, Van Dam NM, Dicke M, Bullock JM, Harvey JA. Genetic variation in defense chemistry in wild cabbages affects herbivores and their endoparasitoids. Ecology 2008; 89(6) 1616-1626.

[44] Morse DH. Size and development times of herbivorous host and parasitoid on distantly related foodplants. The American Midland Naturalist 2011; 166(2) 252-265.

[45] Schuler MA. The role of cytochrome P450 monooxygenases in plant-insect interactions. Plant Physiology 1996; 112(4) 1411.

[46] Ehrlich PR, Raven PH. Butterflies and Plants A Study in Coevolution. Evolution 1964; 18(4)586-608.

[47] Agrawal AA, Kurashige NS. A role for isothiocyanates in plant resistance against the specialist herbivore Pieris rapae. Journal of Chemical Ecology 2003; 29(6) 1403-1415.

[48] Orr DB, Boethel DJ. Influence of plant antibiosis through four trophic levels. Oecologia 1986; 70(2) 242-249.

[49] Harvey JA, Van Dam NM, Gols R. Interactions over four trophic levels foodplant quality affects development of a hyperparasitoid as mediated through a herbivore and its primary parasitoid. Journal of Animal Ecology 2003; 72 (3) 520-531.

[50] Lambert AM. Effects of prey availability, facultative plant feeding, and plant defenses on a generalist insect predator. Arthropod-Plant Interactions 2007; 1(3) 167-173.

[51] Bolton B, Ficken L. Identification guide to the ant genera of the world. Cambridge Harvard University Press; 1994.

[52] Fajer ED, Bowers MD, Bazzaz FA. The effect of nutrients and enriched CO2 environments on production of carbon-based allelochemicals in Plantago a test of the carbon/ nutrient balance hypothesis. American Naturalist 1992; 707-723. 
[53] Lincoln DE, Fajer ED, Johnson RH. Plant-insect herbivore interactions in elevated CO2 environments. Trends in Ecology \& Evolution 1993; 8(2) 64-68.

[54] Lindroth RL, Kinney KK, Platz CL. Responses of diciduous trees to elevated atmospheric $\mathrm{CO}_{2}$ productivity, phytochemistry, and insect performance. Ecology 1993; 763-777.

[55] Gleadow RM, Foley WJ, Woodrow IE. Enhanced $\mathrm{CO}_{2}$ alters the relationship between photosynthesis and defence in cyanogenic Eucalyptus cladocalyx F. Muell. Plant, Cell \& Environment 1998; 21(1) 12-22.

[56] Stiling P, Moon DC. Quality or quantity the direct and indirect effects of host plants on herbivores and their natural enemies. Oecologia 2005;142(3) 413-420.

[57] Stiling P, Cornelissen T. How does elevated carbon dioxide $\left(\mathrm{CO}_{2}\right)$ affect plant-herbivore interactions? A field experiment and meta-analysis of $\mathrm{CO}_{2}$-mediated changes on plant chemistry and herbivore performance.Global Change Biology 2007; 13(9) 1823-1842.

[58] Stamp NE, Temple MP, Traugott MS, Wilkens RT. Temperature-allelochemical interactive effects on performance of Manduca sexta caterpillars. Entomologia Experimentalis et Applicata 1994; 73(3) 199-210.

[59] Veteli TO, Kuokkanen K, Julkunen-Tiittor, Roininen H, Tahvanainen J. Effects of elevated $\mathrm{CO}_{2}$ and temperature on plant growth and herbivore defensive chemistry. Global Change Biology 2002; 8(12) 1240-1252.

[60] Müller-Schärer H, Schaffner U, Steinger T. Evolution in invasive plants implications for biological control. Trends in Ecology \& Evolution 2004; 19(8) 417-422.

[61] Keane RM, Crawley MJ. Exotic plant invasions and the enemy release hypothesis. Trends in Ecology \& Evolution 2002; 17(4) 164-170.

[62] Joshi J, Vrieling K. The enemy release and EICA hypothesis revisited incorporating the fundamental difference between specialist and generalist herbivores. Ecology Letters 2005; 8(7) 704-714.

[63] Liu H, Stiling P, Pemberton RW. Does enemy release matter for invasive plants? Evidence from a comparison of insect herbivore damage among invasive, non-invasive and native congeners. Biological Invasions 2007; 9(7) 773-781.

[64] Blossey B, Notzold R. Evolution of increased competitive ability in invasive nonindigenous plants a hypothesis. Journal of Ecology 1995; 887-889.

[65] Doorduin LJ, Vrieling K. A review of the phytochemical support for the shifting defence hypothesis. Phytochemistry Reviews 2011; 10(1) 99-106.

[66] Callaway RM, Ridenour WM. Novel weapons invasive success and the evolution of increased competitive ability. Frontiers in Ecology and the Environment 2004; 2(8) 436-443. 
[67] Barto E, Powell KFR, Cipollini D. How novel are the chemical weapons of garlic mustard in North American forest understories? Biological Invasions 2010; 12(10) 3465-3471.

[68] Engelkes T, Morriën E, Verhoeven KJF, Bezemer TM, Biere A, Harvey JA, McIntyre LM, Tamis WLM, van der Putten WH. Successful range-expanding plants experience less above-ground and below-ground enemy impact. Nature 2008; 456(7224) 946-948.

[69] Wolfe LM, Elzinga JA, Biere A. Increased susceptibility to enemies following introduction in the invasive plant Silene latifolia. Ecology Letters 2004; 7(9) 813-820.

[70] Morriën E, Engelkes T, Macel M, Meisner A, Van der Putten WH. Climate change and invasion by intracontinental range-expanding exotic plants the role of biotic interactions. Annals of Botany 2010; mcq064.

[71] Cunze S, Leiblein MC, Tackenberg O. Range expansion of Ambrosia artemisiifolia in Europe is promoted by climate change. ISRN Ecology; 2013.

[72] Pearson RG, Dawson TP. Predicting the impacts of climate change on the distribution of species are bioclimate envelope models useful? Global Ecology and Biogeography 2003; 12(5) 361-371.

[73] Fortuna TM, Eckert S, Harvey JA, Vet LEM, Müller C, Gols R. Variation in plant defences among populations of a range-expanding plant consequences for trophic interactions. New Phytologist; 2014.

[74] Huberty M, Tielbörger K, Harvey JA, Müller C, Macel M. Chemical Defenses (Glucosinolates) of Native and Invasive Populations of the Range Expanding Invasive Plant Rorippa austriaca. Journal of Chemical Ecology 2014; 40(4) 363-370.

[75] Paré PW, Tumlinson JH. Plant volatiles as a defense against insect herbivores. Plant Physiology 1999; 121(2) 325-332.

[76] Dudareva N, Pichersky E, Gershenzon J. Biochemistry of plant volatiles. Plant Physiology 2004; 135(4) 1893-1902.

[77] Baldwin IT. Plant volatiles. Current Biology 2010; 20(9) 392-397.

[78] Dicke M, Baldwin IT. The evolutionary context for herbivore-induced plant volatiles beyond the 'cry for help'. Trends in Plant Science 2010; 15(3) 167-175.

[79] Hare JD. Ecological role of volatiles produced by plants in response to damage by herbivorous insects. Annual Review of Entomology 2011; 56 161-180.

[80] Kessler A, Heil M. The multiple faces of indirect defences and their agents of natural selection. Functional Ecology 2011; 25(2) 348-357.

[81] Heil M. Herbivore-induced plant volatiles targets, perception and unanswered questions. New Phytologist 2014. 
[82] Bruce TJA, Wadhams LJ, Woodcock CM. Insect host location a volatile situation. Trends in Plant Science 2005; 10(6) 269-274.

[83] Turlings TCJ, Ted CJ, James H. Tumlinson, and W. J. Lewis. Exploitation of herbivore-induced plant odors by host-seeking parasitic wasps. Science 1990; 250(4985) 1251-1253.

[84] De Moraes CM, Lewis WJ, Pare PW, Alborn HT, Tumlinson JH. Herbivore-infested plants selectively attract parasitoids. Nature 1998; 393(6685) 570-573.

[85] Wajnberg E, Colazza S. Chemical ecology of insect parasitoids. John Wiley \& Sons; 2013.

[86] Gols R. Direct and indirect chemical defences against insects in a multitrophic framework. Plant, Cell \& Environment 2014.

[87] Fortuna TM, Woelke JB, Hordijk CA, Jansen JJ, van Dam NM, Vet LEM, Harvey JA. A tritrophic approach to the preference-performance hypothesis involving an exotic and a native plant. Biological Invasions 2013; 15 (11)2387-2401.

[88] Yuan JS, Himanen SJ, Holopainen JK, Chen F, Stewart CN Jr. Smelling global climate change mitigation of function for plant volatile organic compounds. Trends in Ecology \& Evolution 2009; 24(6) 323-331.

[89] Tauber MJ, Tauber CA. Insect seasonality diapause maintenance, termination, and postdiapause development. Annual Review of Entomology 1976; 21(1) 81-107.

[90] Chapman RF. The insects structure and function. Cambridge university press; 1998.

[91] Saulich AKh, Musolin DL. Diapause in the seasonal cycle of stink bugs (Heteroptera, Pentatomidae) from the Temperate Zone. Entomological Review 2012; 92(1) 1-26.

[92] Sánchez-Guillén RA, Muñoz J, Rodríguez-Tapia G, Arroyo TPF, Córdoba-Aguilar A. Climate-Induced Range Shifts and Possible Hybridisation Consequences in Insects. PloS one 2013; 8(11) e80531.

[93] Groenen F, Meurisse N. Historical distribution of the oak processionary moth Thaumetopoea processionea in Europe suggests recolonization instead of expansion. Agricultural and Forest Entomology 2012; 14(2) 147-155.

[94] Battisti A, Stastny M, Buffo E, Larsson S. A rapid altitudinal range expansion in the pine processionary moth produced by the 2003 climatic anomaly. Global Change Biology 2006; 12(4) 662-671.

[95] Battisti A, Stastny M, Netherer S, Robinet C, Schopf A, Roques A, Larsson S. Expansion of geographic range in the pine processionary moth caused by increased winter temperatures. Ecological Applications 2005; 15(6) 2084-2096. 
[96] Lamy M, Novak F. The oak processionary caterpillar (Thaumetopoea processionea L.) an urticating caterpillar related to the pine processionary caterpillar (Thaumetopoea pityocampa Schiff.)(Lepidoptera, Thaumetopoeidae). Experientia 1987; 43(4) 456-458.

[97] Carroll AL, Taylor SW, Régnière J, Safranyik L. Effect of climate change on range expansion by the mountain pine beetle in British Columbia. In Pages 223-232 in TL Shore et al.(eds) Mountain Pine Beetle Symposium Challenges and Solutions, Oct. 30-31, 2003. Kelowna BC. Natural Resources Canada, Infromation Report BC-X-399, Victoria; 2003.

[98] Desurmont GA, Harvey JA, van Dam NM, Cristescu SM, Schiestl FP, Cozzolino S, Anderson $\mathrm{P}$ et al. Alien interference disruption of infochemical networks by invasive insect herbivores. Plant, Cell \& Environment 2014.

[99] Furlong MJ, Wright DJ, Dosdall LM. Diamondback moth ecology and management problems, progress, and prospects. Annual Review of Entomology 2013; 58 517-541.

[100] Jepsen JU, Hagen SB, Ims RA, Yoccoz NG. Climate change and outbreaks of the geometrids Operophtera brumata and Epirrita autumnata in subarctic birch forest evidence of a recent outbreak range expansion. Journal of Animal Ecology 2008; 77(2) 257-264.

[101] Fei M, Gols R, Harvey JA. Seasonal phenology of interactions involving short-lived annual plants, a multivoltine herbivore and its endoparasitoid wasp. Journal of Animal Ecology 2014; 83(1) 234-244.

[102] Bezemer TM, Harvey JA, Cronin JT. Response of native insect communities to invasive plants. Annual Review of Entomology 2014; 59 119-141.

[103] Gange AC, Brown VK. Soil food web components affect plant community structure during early succession. Ecological Research 2002; 17(2) 217-227.

[104] Petchey OL. Integrating methods that investigate how complementarity influences ecosystem functioning. Oikos 2003; 101(2) 323-330.

[105] Thebault E, Loreau M. The relationship between biodiversity and ecosystem functioning in food webs. Ecological Research 2006; 21(1) 17-25.

[106] Vitousek PM. Beyond global warming ecology and global change. Ecology 1994; 75(7) 1861-1876.

[107] Gibson CC, Ostrom E, Ahn T-K. The concept of scale and the human dimensions of global change a survey. Ecological Economics 2000; 32(2) 217-239.

[108] Sutherst RW. Global change and human vulnerability to vector-borne diseases. Clinical Microbiology Reviews 2004; 17(1) 136-173.

[109] Halpern BS, Walbridge S, Selkoe KA, Kappel CV, Micheli F, D'Agrosa C, Bruno JF et al. A global map of human impact on marine ecosystems. Science; 319 (5865) 948-952. 
[110] Kremen C. Managing ecosystem services what do we need to know about their ecology? Ecology Letters 2005; 8(5) 468-479.

[111] Schweiger O, Settele J, Kudrna O, Klotz S, Kühn I. Climate change can cause spatial mismatch of trophically interacting species. Ecology 2008; 89(12) 3472-3479.

[112] Warren MS, Hill JK, Thomas JA, Asher J, Fox R, Huntley B, Roy DB et al. Rapid responses of British butterflies to opposing forces of climate and habitat change. Nature 2001; 414(6859) 65-69.

[113] Hill MO, Roy DB, Thompson K. Hemeroby, urbanity and ruderality bioindicators of disturbance and human impact. Journal of Applied Ecology 2002; 39(5) 708-720.

[114] Hewitt CD, Broccoli AJ, Mitchell JFB, Stouffer RJ. A coupled model study of the last glacial maximum Was part of the North Atlantic relatively warm? Geophysical Research Letters 2001; 28(8) 1571-1574.

[115] Chakraborty K, Soovoojeet J, Kar TK. Global dynamics and bifurcation in a stage structured prey-predator fishery model with harvesting. Applied Mathematics and Computation 2012; 218(18) 9271-9290.

[116] Kennedy AC, Smith KL. Soil microbial diversity and the sustainability of agricultural soils. Plant and Soil 1995; 170(1) 75-86.

[117] Hu SJ, Van Bruggen AHC, Grünwald NJ. Dynamics of bacterial populations in relation to carbon availability in a residue-amended soil. Applied Soil Ecology 1999; 13(1) 21-30.

[118] Horz H-P, Barbrook A, Field CB, Bohannan BJM. Ammonia-oxidizing bacteria respond to multifactorial global change. Proceedings of the National Academy of Sciences of the United States of America 2004; 101(42) 15136-15141.

[119] Stewart BA, Hatfield JL. Crops residue management. Lewis Publishers; 1994.

[120] Doran JW, Coleman DC, Bezdicek DF, Stewart BA. Microbial indicators of soil quality. 1994.

[121] Di Castri F, Younes T. Ecosystem function of biological diversity. Biological International Special Issue 1990; 22.

[122] Bezemer TM, van Dam NM. Linking aboveground and belowground interactions via induced plant defenses. Trends in Ecology \& Evolution 2005; 20(11) 617-624.

[123] De Deyn, Gerlinde B, Van der Putten WH. Linking aboveground and belowground diversity. Trends in Ecology \& Evolution 2005; 20(11) 625-633.

[124] Bardgett RD, Freeman C, Ostle NJ. Microbial contributions to climate change through carbon cycle feedbacks. The ISME Journal 2008; 2(8) 805-814. 
[125] Zak JC, Willig MR, Moorhead DL, Wildman HG. Functional diversity of microbial communities a quantitative approach. Soil Biology and Biochemistry 1994; 26(9) 1101-1108.

[126] Freeman C, Ostle N, Kang H. An enzymic'latch'on a global carbon store. Nature 2001; 409(6817) 149-149.

[127] Diaz S, Grime JP, Harris J, McPherson E. Evidence of a feedback mechanism limiting plant response to elevated carbon dioxide. Nature 1993; 364(6438) 616-617.

[128] Klironomos J, Rillig M, Allen M, Zak D, Kubiske M, Pregitzer K. Soil fungal-arthropod responses to Populus tremuloides grown under enriched atmospheric $\mathrm{CO} 2$ under field conditions. Global Change Biology 1997; 3(6) 473-478.

[129] Staddon PL, Gregersen R, Jakobsen I. The response of two Glomus mycorrhizal fungi and a fine endophyte to elevated atmospheric $\mathrm{CO}_{2}$, soil warming and drought. Global Change Biology 2004; 10(11) 1909-1921.

[130] Högberg P, Read DJ. Towards a more plant physiological perspective on soil ecology. Trends in Ecology \& Evolution 2006; 21(10) 548-554.

[131] Ström L, Mastepanov M, Christensen TR. Species-specific effects of vascular plants on carbon turnover and methane emissions from wetlands. Biogeochemistry 2005; 75(1) 65-82.

[132] Abawi GS, Widmer TL. Impact of soil health management practices on soilborne pathogens, nematodes and root diseases of vegetable crops. Applied Soil Ecology 2000; 15(1) 37-47.

[133] Packer A, Clay K. Soil pathogens and spatial patterns of seedling mortality in a temperate tree. Nature 2000; 404(6775) 278-281.

[134] Hartley S, Harris R, Lester PJ. Quantifying uncertainty in the potential distribution of an invasive species climate and the Argentine ant. Ecology Letters 2006; 9(9) 1068-1079.

[135] Percy KE, Legge AH, Krupa SV. Tropospheric ozone a continuing threat to global forests? Developments in Environmental Science 2003; 3 85-118.

[136] Mcelrone AJ, Reid CD, Hoye KA, Hart E, Jackson RB. Elevated $\mathrm{CO}_{2}$ reduces disease incidence and severity of a red maple fungal pathogen via changes in host physiology and leaf chemistry.Global Change Biology 2005; 11(10) 1828-1836.

[137] Johnson SN, Staley JT, McLeod FA, Hartley SE. Plant-mediated effects of soil invertebrates and summer drought on above-ground multitrophic interactions. Journal of Ecology 2011; 99(1) 57-65.

[138] Wardle DA, Bonner KI, Barker GM. Linkages between plant litter decomposition, litter quality, and vegetation responses to herbivores. Functional Ecology 2002; 16(5) 585-595. 
[139] Colautti RI, Ricciardi A, Grigorovich IA, MacIsaac HJ. Is invasion success explained by the enemy release hypothesis? Ecology Letters 2004; 7(8) 721-733.

[140] Hilbig W. The vegetation of Mongolia. SPB Publishing,Amsterdam, The Netherlands; 1995.

[141] van Asch M, Visser ME. Phenology of forest caterpillars and their host trees the importance of synchrony. Annual Review of Entomology 2007; 52 37-55.

[142] Thomas B, Vince-Prue D. Photoperiodism in plants. Academic Press; 1996.

[143] Kirschbaum MUF. Will changes in soil organic carbon act as a positive or negative feedback on global warming? Biogeochemistry 2000; 48(1) 21-51.

[144] Berggren Å, Björkman C, Bylund H, Ayres MP. The distribution and abundance of animal populations in a climate of uncertainty. Oikos 2009; 118(8) 1121-1126.

[145] Norby RJ, Luo Y. Evaluating ecosystem responses to rising atmospheric $\mathrm{CO}_{2}$ and global warming in a multi-factor world. New Phytologist 2004; 162(2) 281-293.

[146] Kinnison MT, Hairston NG. Eco-evolutionary conservation biology contemporary evolution and the dynamics of persistence. Functional Ecology 2007; 21(3) 444-454.

[147] Berkhout BW, Lloyd MM, Poulin R, Studer A. Variation among genotypes in responses to increasing temperature in a marine parasite evolutionary potential in the face of global warming? International Journal for Parasitology; 2014.

[148] Jump AS, Hunt JM, Penuelas J. Rapid climate change-related growth decline at the southern range edge of Fagus sylvatica. Global Change Biology 2006; 12(11) 2163-2174.

[149] Jump AS, Hunt JM, Martinez-Izquierdoja JA, Penuelas J. Natural selection and climate change temperature-linked spatial and temporal trends in gene frequency in Fagus sylvatica. Molecular Ecology 2006; 15(11) 3469-3480.

[150] Pimm SL. The balance of nature? ecological issues in the conservation of species and communities. University of Chicago Press; 1991.

[151] Soler R, Van der Putten WH, Harvey JA, Vet LEM, Dicke M, Bezemer TM. Root herbivore effects on aboveground multitrophic interactions patterns, processes and mechanisms. Journal of Chemical Ecology 2012; 38(6) 755-767. 
